\title{
Ciência da informação e organização do conhecimento no Brasil à luz da reflexão epistemológica francesa de análise do discurso
}

\author{
Information Science and Knowledge Organization in Brazil based on the French \\ epistemological reflection of Discourse Analysis
}

\begin{abstract}
Marcos Vinícius Santos de Carvalho Terra Doutorando em Ciência da Informação pela Universidade Estadual Paulista "Júlio de Mesquita Filho" - UNESP, Brasil.

E-mail: marcosetica@gmail.com https://orcid.org/0000-0002-4275-3292

Doutora em Ciência da Informação pela Universidade Estadual Paulista "Júlio de Mesquita Filho" - UNESP, Brasil. Professora do curso de Biblioteconomia e Ciência da Informação da Faculdade de Filosofia, Ciências e Letras de Ribeirão Preto da Universidade de São Paulo - FFCLRP/USP, Brasil.

E-mail: deisemarian@gmail.com https://orcid.org/0000-0001-6392-4719
\end{abstract}

\section{Resumo}

$\mathrm{O}$ artigo explora as interações teóricas estabelecidas entre as linhas francesas de análise do discurso e o campo informacional. O foco deste estudo analítico está nas questões interdisciplinares, bem como nas relações epistemológicas, que esse diálogo apresenta para ciência da informação e a organização do conhecimento. O objetivo é investigar o estabelecimento das relações interdisciplinares desses campos no contexto brasileiro, tendo como caminho metodológico para o entendimento desta perspectiva diacrônica a epistemologia crítica. Três linhas de análise do discurso foram eleitas para efeitos da relação epistemológica: a linha de Michel Pêcheux, a linha da sociolinguística e a linha de Michel Foucault. As teses e as dissertações analisadas revelam que as interações epistemológicas entre as teorias francesas do discurso e o campo informacional se encontram em estudos sobre a epistemologia e a historicidade da ciência da informação, estudos bibliométricos, estudos arquivísticos, estudos sobre a leitura dos profissionais da informação, estudos sobre organização da informação e do conhecimento, estudos metodológicos e estudos sobre representação da informação e do conhecimento.

Palavras-chave: Análise do discurso. Ciência da informação. Organização do conhecimento. Epistemologia.

\begin{abstract}
The article explores the theoretical interactions established between the French lines of Discourse Analysis and the informational field. The focus of this analytical study is on interdisciplinary issues, as well as on epistemological relationships, which this dialogue presents for Information Science and the Knowledge Organization. The objective is to investigate the establishment of the interdisciplinary relations of these fields in the Brazilian context, using the critical epistemology as the methodological path for understanding this diachronic perspective. Three lines of discourse analysis were chosen for the purposes of the epistemological relationship: Michel Pêcheux's approach, sociolinguistic approach and Michel Foucault's approach. The theses and dissertations analyzed reveal that the epistemological interactions between French theories of discourse and the informational field are found in studies on the epistemology and historicity of Information Science, bibliometric studies, archival studies, studies on the reading of information professionals, studies on Information and Knowledge Organization, methodological studies and studies on Information and Knowledge Representation.
\end{abstract}

Keywords: Discourse analysis. Information science. Knowledge organization. Epistemology. 


\section{Introdução}

A interação entre saberes e conhecimentos é possível por meio da interdisciplinaridade. Assim, os campos de interesse necessitam de identidade, para que, mediante visões diferentes, haja a compreensão de um objeto comum. Há, assim, uma complexidade no campo informacional que possibilita uma rede de cooperação científica.

Dessa forma, são necessários enriquecimentos teóricos e conceituais. Nessa perspectiva, os estudos sobre linguagem e sobre discurso devem ser reconhecidos como indispensáveis no campo informacional. Os trabalhos ligados às linhas francesas de análise do discurso, cuja fundamentação teórica está alicerçada nos estudos de Michel Pêcheux, de Michel Foucault e da sociolinguística, permitem o entendimento de como as relações de poder são simbolizadas e sustentadas na ciência da informação e na organização do conhecimento. Por conseguinte, este trabalho investiga como as teorias francesas sobre discurso estabelecem suas interações epistemológicas com a ciência da informação e a organização do conhecimento no Brasil. Expõe, além disso, como as vertentes francesas de análise do discurso auxiliam na interpretação dos processos linguísticos, ideológicos e políticos que se manifestam nos modos de ordenar, representar e disseminar a informação e o conhecimento.

Logo, os modos de organizar e representar a informação e o conhecimento não são neutros, pois estão inseridas em uma dimensão social e política. Eles são dependentes das condições de produção e dos anseios interpretativos dos sujeitos envolvidos nos processos informacionais. As relações de poder, portanto, devem ser consideradas nas pesquisas que tratam a ciência da informação e a organização do conhecimento, as quais são dependentes dos sujeitos que com ela se relacionam.

Em torno da informação e do conhecimento, há conflitos, interesses econômicos, desigualdades, embates políticos. Por meio de pesquisa bibliográfica, ligada às interações interdisciplinares entre as linhas francófonas de análise do discurso, a ciência da informação e a organização do conhecimento no contexto brasileiro, foi feito um levantamento de trabalhos sobre o mote ao longo dos anos, a fim de se ter uma compreensão das relações epistemológicas entre esses campos.

Assim, os aspectos epistemológicos que permeiam as teorias do discurso e o campo informacional revelam como a informação e o conhecimento estão inseridos em embates sociais 
e políticos. Logo, o percurso teórico realizado até aqui revela que a análise do discurso auxilia na compreensão das disputas de poder, das relações de força e dos fenômenos ideológicos presentes na ciência da informação e na organização do conhecimento.

\section{Percurso metodológico}

Em um horizonte cheio de desafios, busca-se a compreensão dos elos entre as linhas francesas de análise do discurso e o campo informacional, isto é, o que existe no entremeio das teorias, como elas se entrecruzam, como funcionam os seus movimentos epistemológicos.

A fim de investigar como a ciência da informação e a organização do conhecimento, no contexto brasileiro, estabelecem sua dinâmica interdisciplinar com diferentes vertentes francesas de análise do discurso, optou-se pela análise crítica de reflexão epistemológica. Para isso, foram retomados os estudos feitos por Hilton Japiassu e Pierre Bourdieu. Por conseguinte, nessa investigação científica, o processo interpretativo do material encontrado, pertinente ao tema proposto, teve um enfoque crítico, a partir dos autores citados acima.

A epistemologia crítica, por conseguinte, foi utilizada para o cumprimento dos objetivos deste trabalho que visa mostrar algumas das principais contribuições epistemológicas das linhas francesas de análise do discurso para o campo informacional e os avanços conceituais que afloraram a partir dessa interação. À vista disso, é mister ressaltar que não se trata de uma análise bibliométrica, mas sim conceitual, com um olhar analítico para as ideias e para os trabalhos.

Por meio de pesquisa bibliográfica, ligada às interações entre as correntes de análise do discurso francesa, a ciência da informação e a organização do conhecimento, foi feita uma sondagem de pesquisas produzidas sobre o mote ao longo dos anos, para se ter uma compreensão das relações interdisciplinares entre os campos.

A fim de identificar as diferentes linhas de análise do discurso francesa na ciência da informação e na organização do conhecimento no contexto brasileiro, a partir de uma perspectiva exploratória, foi feito um levantamento bibliográfico, por meio da localização de teses e dissertações na Biblioteca Digital Brasileira de Teses e Dissertações (BDTD), Biblioteca Digital de Teses e Dissertações da USP e Repositório Institucional de Geociências 
Assim, foram encontrados 22 trabalhos sobre o tema no período de 1996 a 2018. Desses trabalhos, seis utilizam apenas a análise do discurso pecheuxtiana; nenhuma pesquisa utiliza apenas a vertente sociolinguística; e nove utilizam somente a vertente foucaultiana; sete relacionam os trabalhos de Pêcheux e Foucault; e três relacionam os estudos de Pêcheux, de Foucault e da sociolinguística.

Gráfico 1 - Análise do Discurso na CI e OC

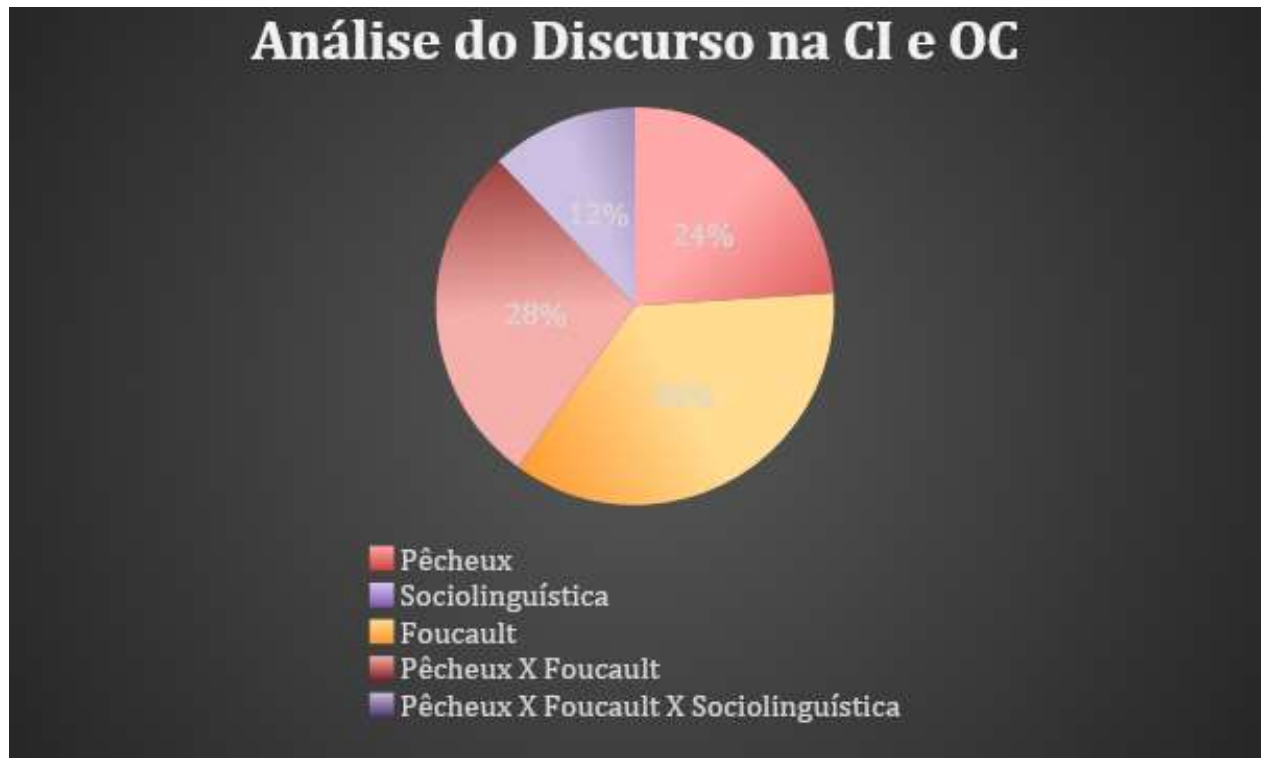

Fonte: Elaborado pelos autores

As dissertações e as teses recuperadas foram dos seguintes autores: Lucas (1996), Alvarenga (1996), Rocha (1999), Azevedo Netto (2001), Freitas (2001), Cordeiro (2004), Oddone (2004), Lima (2004), Souza (2008), Ferrarezi (2010), Barros (2010), Souza (2011), Reis (2012), Santos (2013), Novo (2014), Barros (2014), Silva (2014), Milani (2014), Elias (2017), Lima (2017), Barros (2017) e Caprioli (2018).

Os trabalhos encontrados foram categorizadas em grupos temáticos, a saber: estudos sobre a epistemologia e a historicidade da ciência da informação (FREITAS, 2001; ODDONE, 2004; SOUZA, 2011; LIMA, 2017), estudos bibliométricos (ALVARENGA, 1996; LIMA, 2004), estudos arquivísticos (BARROS, 2010; BARROS, 2014; BARROS, 2017; ELIAS, 2017; estudos sobre a leitura dos profissionais da informação (LUCAS, 1996; ROCHA, 1999; FERRAREZI, 2010; SILVA, 2014), estudos sobre organização da informação e do conhecimento (SOUZA, 2008; SANTOS, 2013; REIS, 2012), estudos metodológicos (CORDEIRO, 2004; CAPRIOLI, 2018) e estudos sobre representação da informação e do conhecimento (AZEVEDO NETTO, 2001; NOVO, 2014; MILANI; 2014). 

epistemológica francesa de análise do discurso

Destarte, é mister o reconhecimento de que há diferentes vertentes francesas de análise do discurso inseridas na ciência da informação e na organização do conhecimento. Nessa investigação científica, optou-se por analisar as interações interdisciplinares entre as vertentes francófonas que emergiram nos anos 1960, mesmo ano em que afloraram os estudos sobre análise documentária na França. As linhas escolhidas estão ligadas a Pêcheux, a Foucault e à sociolinguística.

\section{Análise do discurso francesa: Pêcheux, Foucault e a sociolinguística}

No contexto francês, nos anos 1960, os pesquisadores ligados às teorias discursivas foram divididos em diferentes grupos de esquerda, de acordo com o posicionamento político de cada um. Outro fator determinante para a segmentação dos intelectuais foram as posições tomadas em torno da linguística. Assim, os estudos discursivos têm diferentes desdobramentos.

Dessa forma, a análise do discurso francesa tem se ramificado em diferentes ordens teóricas e metodológicas. É importante considerar também que existem, no campo científico, relações de força e poder, as quais atravessam as classificações, as diferenças e as considerações desses desdobramentos. A ciência é construída em diferentes lugares com a força e as particularidades de cada tradição (ORLANDI, 2003).

Nesse horizonte, salienta-se que os estudos francófonos sobre discurso são caracterizados pela pluralidade de trabalhos. Entre esses desdobramentos, encontram-se os estudos de Michel Pêcheux, de Michel Foucault e da sociolinguística, representada por nomes como: Jean Dubois, Jean Baptiste Marcellesi, Bernard Gardin e Louis Guespin

Cada vertente apresenta sua especificidade, com pontos de aproximação e com pontos de afastamento (GADET 2015; NARZETTI, 2010). Esses autores estão vinculados ao surgimento da análise do discurso no contexto francês. Logo, são os principais representantes de cada vertente.

A vertente ligada a Michel Pêcheux está alicerçada em três domínios disciplinares, a saber, a linguística, de Saussure; o materialismo histórico, de Marx; e a psicanálise, de Freud. Pêcheux, em sua teoria, também foi fortemente influenciado por Lacan e por Althusser, sobretudo, no que tange ao inconsciente e à ideologia na constituição do sujeito. Althusser, em 
sua releitura de Marx; Lacan, em releitura de Freud (ORLANDI, 2003, 2007). Todo processo discursivo, segundo Pêcheux (1995, p. 92), se inscreve numa relação ideológica de classes.

A vertente foucaultiana de análise do discurso, por outro lado, não está situada na linguística. Embora trate do discurso, não realiza uma análise do sentido. A análise arqueológica busca o fato do aparecimento histórico de um discurso. Vale ressaltar que o estudo do saber, em Foucault, não está limitado à análise do discurso ou dos regimes de enunciabilidade (NARZETTI, 2010). Para ele, "o discurso é algo inteiramente diferente do lugar em que vem se depositar e se superpor, como em uma simples superfície de inscrição, objetos que teriam sido instaurados anteriormente" (FOUCAULT, 2008, p. 48).

Surgiram também, nos anos sessenta, novas questões em torno do estruturalismo. Nesse horizonte, a linguística desempenha um papel de liderança. O projeto intelectual da sociolinguística é interdisciplinar em seus próprios fundamentos, uma vez que representa o encontro de duas disciplinas, a saber, a sociologia e a linguística (BOUTET; MAINGUENEAU, 2005).

A vertente sociolinguística de análise do discurso, assim sendo, tem a Linguística como seu solo epistemológico, no entanto uma linguística ampliada, renovada, a qual não deixa de fora de suas análises os aspectos sociais, que não foram problematizados pela linguística estruturalista. Na perspectiva de Marcellesi e sua equipe, a análise de discurso faz parte do domínio particular da sociolinguística (NARZETTI, 2010; ORLANDI, 2003). É importante registrar que as análises sociolinguísticas do discurso são marcadas por exames contrastivos e comparativos que valorizam o discurso político (MARCELLESI, 1971).

As diferentes perspectivas discursivas, presentes em pesquisas sobre informação, revelam que as filiações teóricas podem produzir diferentes sentidos sobre o posicionamento político dos agentes e também das instituições de pesquisas. Destarte, os trabalhos científicos interdisciplinares entre as diferentes correntes de análise do discurso francófona e o campo informacional possuem um viés político que deve ser considerado. 


\section{Ciência da informação e organização do conhecimento}

Os gestos de leituras referentes à presença das vertentes francesas de análise do discurso na ciência da informação e na organização do conhecimento possibilitam reflexões sobre as diferentes formas de interação epistemológica entre os campos do saber ao longo dos anos. Essas reflexões auxiliam no entendimento teórico e apontam caminhos para um amadurecimento das interações científicas. Vale ressaltar que não faz parte do objetivo deste trabalho analisar os fundamentos da análise do discurso francófona e do campo informacional, mas sim refletir sobre a dialogicidade entre as duas áreas no contexto brasileiro.

A ciência da informação é conhecida por ser uma ciência interdisciplinar, ou seja, por estar aberta à cooperação científica e ao diálogo com outras áreas do saber. Além disso, por ser uma ciência cuja informação é seu objeto; por ser capaz de dialogar com disciplinas sociais; e por estar inserida no contexto de novas tecnologias de informação e comunicação.

Nota-se que a ciência da informação se apresenta como um campo teórico capaz de dialogar com outras áreas do conhecimento, dado que seu objeto de estudo, a informação, está inserido em fenômenos complexos. Posto isso, os estudos informacionais atraem pesquisadores com diferentes características e enfoques. Nesses movimentos interdisciplinares, busca-se, por conseguinte, a investigação de questões tecnológicas, sociais, linguísticas em torno da informação.

Por sua vez, a organização do conhecimento, segundo Birger Hjørland (2008), envolve atividades ligadas à descrição, à indexação e à classificação de documentos, que podem ser realizadas em bibliotecas, bancos de dados e arquivos, por exemplo. O pesquisador pondera que essas atividades podem ser feitas por diferentes profissionais da informação, a saber, bibliotecários, arquivistas e outros especialistas, bem como por algoritmos de computador.

De acordo com o teórico, há, na organização do conhecimento, diferentes perspectivas históricas e teóricas que se relacionam com diferentes visões de conhecimento, cognição, linguagem e organização social. Sendo assim, os sistemas de organização são inclinados para alguma posição filosófica. O conhecimento não pode ser organizado por uma plataforma neutra (HJØRLAND, 2008).

Para Sales (2015), a relação entre a organização do conhecimento e a ciência da informação é um tema que apresenta diferentes perspectivas na literatura da área. Sendo assim, 
não há um consenso sobre o assunto. Existe uma tradição que insere a organização do conhecimento como parte integrante da ciência da informação. Por outro lado, existem estudos que preferem tratá-la como uma área separada da ciência da informação.

No cenário brasileiro, o autor defende que, quanto à sua natureza, a organização do conhecimento é um território científico com autonomia, ainda que esteja em constante diálogo com a ciência da informação. Desse modo, se apresenta como um espaço emergente com seus próprios contornos epistemológicos (SALES, 2015). Em outros dizeres, a organização do conhecimento é autônoma, mas com fortes interações com a ciência da informação.

Para Martins e Moraes (2015, p. 20), a organização e representação do conhecimento evoluiu interagindo com outras áreas científicas por ser considerado um campo de investigação independente, além de ter legitimidade como um subcampo de uma ciência interdisciplinar. Em fase de consolidação, com avanços teóricos e distintas influências teóricas, a organização do conhecimento cumpre um papel nuclear na ciência da informação (MATOS; GUIMARÃES; GRÁCIO, 2015).

De acordo com Guimarães (2017, p. 90), na organização do conhecimento, elementos foram se transformando ou se ressignificando, como por exemplo, o enfoque linguístico e terminológico que abre espaço para abordagens mais discursivas, além da crescente busca pela contextualização e pela dialogicidade em interações interdisciplinares e culturais. $\mathrm{O}$ autor também ressalta que o campo está em busca de uma identidade, visto que a questão epistemológica permanece como uma constante.

Dessa forma, crescem as atividades investigativas e a produção científica no âmbito da organização do conhecimento (GUIMARÃES, 2017). Assim, a “organização do conhecimento constitui um campo científico de configuração interdisciplinar que vem buscando, ao longo do tempo, consolidar sua identidade enquanto tal" (GUIMARÃES, 2017, p. 92). 


\section{Análise dos resultados}

Pierre Bourdieu (2004) assinala que o campo científico é o universo, no qual estão inseridos agentes e instituições que produzem, reproduzem e difundem a ciência. Trata-se de um campo de forças, de um campo de lutas, de um mundo social que comporta relações de dominação. Os pontos de vista, as intervenções científicas, os lugares de publicação, os temas escolhidos, os objetos de pesquisas são comandados pela estrutura das relações objetivas entre os diferentes agentes. Logo, é a posição que se ocupa nessa estrutura que determina o que pode e o que não pode ser feito.

Falar de epistemologia, na visão de Japiassu (1977), é se engajar num espaço polêmico e de conflitos. Embora pareça um termo antigo, surgiu a partir do século XIX no vocabulário filosófico. Seu significado etimológico é discurso (logos) sobre a ciência (episteme). Trata-se de uma disciplina cuja construção é lenta e recente. Entende-se epistemologia, no sentido amplo do termo, como o estudo metódico e também reflexivo do saber, no qual sua organização, sua formação, seu desenvolvimento, seu funcionamento e seus produtos intelectuais são considerados.

É importante considerar que o conhecimento científico está inserido em determinados contextos socioculturais. É, por conseguinte, tributário de fatores ligados à religião, à política, à ideologia, à filosofia e à economia. A ciência tem seus objetivos, seus agentes e seu modo de funcionamento condicionados a uma sociedade determinada. Portanto, o conhecimento científico é também uma forma de poder (JAPIASSU, 1977).

Não se pode esquecer que os conflitos intelectuais, conforme aponta Bourdieu (2004), são também conflitos de poder. Semelhantemente ao mundo econômico, o mundo científico conhece relações de força, fenômenos de concentração de capital e de poder, até mesmo de monopólio, além de relações sociais de dominação, as quais implicam uma apropriação dos meios de produção e de reprodução, ademais conhece lutas que refletem o controle dos meios de produção e reprodução específicos.

Sob esse prisma da vertente crítica epistemológica, as dissertações e teses com interações epistemológicas entre o campo discursivo e o campo informacional foram categorizados tematicamente da seguinte forma:

a) Estudos sobre a epistemologia e a historicidade da ciência da informação; 
b) Estudos bibliométricos;

c) Estudos arquivísticos;

d) Estudos sobre a leitura dos profissionais da informação;

e) Estudos sobre organização da informação e do conhecimento;

f) Estudos metodológicos; e

g) Estudos sobre representação da informação e do conhecimento.

Os trabalhos foram classificados tematicamente, conforme o Quadro 1:

Quadro 1 - Classificação temática dos trabalhos

\begin{tabular}{|l|l|}
\hline $\begin{array}{l}\text { TEMÁTICA Estudos sobre a epistemologia e a historicidade da ciência da } \\
\text { informação }\end{array}$ & $\begin{array}{l}\text { Freitas (2001) } \\
\text { Oddone (2004) } \\
\text { Souza (2011) } \\
\text { Lima (2017) }\end{array}$ \\
\hline b) Estudos bibliométricos & $\begin{array}{l}\text { Alvarenga (1996) } \\
\text { Lima (2004) }\end{array}$ \\
\hline c) Estudos arquivísticos & $\begin{array}{l}\text { Barros (2010) } \\
\text { Barros (2014) } \\
\text { Elias (2017) } \\
\text { Barros (2017) }\end{array}$ \\
\hline d) Estudos sobre a leitura dos profissionais da informação & $\begin{array}{l}\text { Lucas (1996) } \\
\text { Rocha (1999) }\end{array}$ \\
& $\begin{array}{l}\text { Ferrarezi (2010) } \\
\text { Silva (2014) }\end{array}$ \\
\hline e) Estudos sobre organização da informação e do conhecimento & $\begin{array}{l}\text { Souza (2008) } \\
\text { Reis (2012) } \\
\text { Santos (2013) }\end{array}$ \\
\hline Cordeiro (2004) \\
Caprioli (2018)
\end{tabular}

Fonte: Elaborado pelos autores

Em relação aos estudos sobre a epistemologia e a historicidade da ciência da informação, nota-se que existe uma convergência entre os trabalhos de Freitas (2001) e Souza (2011), na medida em que os dois teóricos discorrem sobre a presença neoliberal no discurso da ciência da informação. Ao utilizarem a análise do discurso em suas pesquisas, os dois autores citados fazem emergir um embate político na epistemologia do campo informacional, a saber, de um lado, os estudos sobre discurso que se alinham a um posicionamento de esquerda; do outro, as pesquisas sobre informação que atendem aos interesses do mercado.

Já a pesquisa de Lima (2017) contribui com a intersecção entre a linguística e a ciência da informação, sobretudo no que concerne às questões sobre discurso, análise documentária e 
organização do conhecimento. Por conseguinte, seu trabalho, a partir dos estudos franceses de análise do discurso, traz reflexões teórico-metodológicas sobre conceitos fundamentais para a ciência da informação. Salienta-se também que, nesse percurso teórico, a análise do discurso auxiliou na compreensão do papel da ANCIB e do ENANCIB na legitimação das tendências de pesquisa na área.

A análise do discurso francófona, por sua vez, nos estudos de Oddone (2004), traz subsídios para o entendimento da historicidade do campo informacional, recuperando marcos históricos e compreendendo como a área é entendida em sua perspectiva histórica pelos seus profissionais e pelas suas instituições.

Nos estudos bibliométricos, as pesquisas de Alvarenga (1996) e Lima (2004) assinalam para uma articulação entre estudos bibliométricos e arqueologia de Foucault. Nesse cenário, verifica-se que ambos os trabalhos revelam que os enunciados estão privilegiando pontos vinculados ao mercado e ao sistema capitalista. Realça-se também que a análise do discurso francófona se apresenta como uma metodologia capaz de auxiliar na interpretação e na análise de dados de modo crítico, problematizando os resultados.

No que tange aos estudos arquivísticos, sob o prisma da análise do discurso, Barros (2010) buscou identificar os sujeitos que enunciam e os lugares nos quais os conceitos são enunciados na arquivística. O pesquisador também identificou as tradições arquivísticas presentes nos países dos manuais trabalhados em sua investigação científica.

Segundo Barros (2014), a análise do discurso pode contribuir com as discussões sobre as posições ideológicas em dada conjuntura presentes na arquivística e nas instituições responsáveis pela organização de documentos de arquivos. Posto que, no espaço discursivo, é possível outros olhares e análises. Logo, pesquisas de ordem epistemológica são necessárias para a arquivística.

Nos trabalhos de Elias (2017) e Barros (2017), ambos desenvolvidos na Universidade de Brasília e sob orientação da professora Georgete Medleg Rodrigues, ocorrem análises discursivas de documentos de cunho político e de forte interesse nacional. As autoras problematizam aspectos ligados ao arquivo em sua relação com o campo político.

Nos estudos sobre a leitura dos profissionais da informação, Lucas (1996), Rocha (1999), Ferrarezi (2010) e Silva (2014) compartilham da ideia de que há sentidos dominantes 
presentes nos padrões de classificação. Por conseguinte, surge a necessidade de abertura para sentidos que sejam mais abrangentes, atendendo a complexidade da sociedade.

Mesmo que Lucas (1996), Ferrarezi (2010) e Silva (2014) utilizem os estudos de Pêcheux e Orlandi na biblioteconomia, enquanto Rocha (1999) se fundamenta em Foucault na Museologia, chegam a conclusões parecidas, isto é, a importância da negociação de subjetividades e de leituras que sejam mais plurais por parte dos profissionais da informação. Elas assinalam para um conceito de leitura que esteja aberto à polissemia e que possibilite múltiplas interpretações. Destarte, as autoras problematizam a noção de leitura e a busca pelo controle dos sentidos no campo informacional.

Nos estudos sobre organização da informação e do conhecimento, Souza (2008) trouxe reflexões sobre como a ciência da informação pode contribuir com a compreensão de temas complexos que envolvam a ciência, a política, a economia e a legislação numa perspectiva multidisciplinar e interdisciplinar. Reis (2012), por seu turno, prioriza um modo mais dialógico de organização, isto é, a folksonomia. Esse instrumento de organizar e classificar informações funciona como um instrumento de auxílio que, na utilização de linguagens documentárias, considera o sujeito e o contexto de uso da informação. Além disso, permite que uma pessoa atribua tags, isto é, palavras escolhidas para representar conteúdo online. Santos (2013), por sua vez, defende que é possível, mediante a análise discursiva, agrupar e relacionar documentos, considerando materialidades textuais com diferentes características.

Os estudos metodológicos de Cordeiro (2004) e de Caprioli (2018) assinalam para uso da análise do discurso francófona como uma metodologia capaz de auxiliar em questões interpretativas, tão importantes para a recuperação da informação. Para Caprioli (2018), os estudos sobre discursos oferecem subsídios para as peculiaridades dos textos literários.

No que tange aos estudos sobre representação da informação e do conhecimento, Azevedo Netto (2001) argumenta que os sistemas de representação construídos pelos arqueólogos brasileiros mantêm uma relação estrita com as construções discursivas desses pesquisadores. Nesse sentido, a análise das representações da arte rupestre brasileira pode dialogar com a análise de discurso, posto que Foucault analisa a construção das estruturas discursivas.

Novo (2014) utilizou a análise do discurso representativo de Foucault, buscando analisar a enunciação discursiva de textos. A pesquisadora se preocupa em compreender como o sujeito 
processa e usa dinâmica e cognitivamente a informação, para elaborar mecanismos de análise conceitual que possibilitem um modelo dinâmico, a fim de auxiliar na construção de sistemas de organização e representação do conhecimento.

Para Milani (2014), os instrumentos de representação de assunto refletem a cultura dominante de uma sociedade. Dessa forma, desempenham um papel-chave nas bibliotecas. No contexto negativo, um instrumento de representação de assunto contendo bias $^{1}$, podem veicular preconceitos. No contexto positivo, podem garantir as especificidades das comunidades usuárias por meio da representação de assunto. Por conseguinte, a autora busca contextualizar o fenômeno das biases e auxiliar na atenuação de seus efeitos.

\section{Considerações finais}

Os trabalhos interdisciplinares, com ênfase no discurso, na ciência da informação e na organização do conhecimento, apontam que os processos em torno da informação não são neutros e apolíticos. Nesse sentido, as vertentes francófonas de análise do discurso, especialmente os estudos de Pêcheux e da vertente sociolinguística, trouxeram uma visão marxista dos modos de ordenar e classificar a informação, identificando os museus, bibliotecas e arquivos como aparelhos ideológicos do Estado. Nessa abordagem marxista dos aspectos linguísticos, a linguagem se apresenta como um campo de tensões e de disputas de poder.

No cenário epistemológico da ciência da informação, a análise do discurso contribuiu com reflexões sobre a tensão em torno dos sentidos presentes na área, isto é, de um lado, uma tendência de ligar as pesquisas em informação ao discurso neoliberal; do outro, a busca por discursos mais humanísticos e sociais. Portanto, as pesquisas realizadas revelaram que os discursos ligados ao mercado são bem presentes na epistemologia da área. Além disso, os estudos sobre discurso ofereceram subsídios para a identificação de órgãos que legitimam as tendências das pesquisas informacionais e na clarificação de aspectos ligados à historicidade da área.

\footnotetext{
${ }^{1}$ Bias(es): A autora Suellen Milani (2014) explica que o termo bias(es), na área de organização da informação, é polissêmico. Justamente por isso ela o utiliza em sua versão original em inglês, pois, na língua portuguesa, ele tem conotações negativas que se referem à tendência, à inclinação ou ao desvio, além disso, tem conotações de direcionamento ou viés. Neste contexto, a autora explica as bias (es) nos instrumentos de representação da informação, sendo que sua presença, negativa ou positiva, é inevitável. Destarte, o processo de representação nunca é neutro.
} 

epistemológica francesa de análise do discurso

A bibliometria também recebeu importantes contribuições da análise do discurso, sobretudo, dos estudos foucaultianos. Os trabalhos analisados apontam que há relações de poder nas citações. Nesse sentido, a análise do discurso se apresenta como uma metodologia capaz de contribuir criticamente com a interpretação e com a análise de dados.

Nota-se também que uma das grandes contribuições conceituais da análise do discurso para a ciência da informação e para organização do conhecimento está no conceito de leitura. Os trabalhos interdisciplinares, envolvendo os pensamentos de Pêcheux e de Foucault, no campo informacional, problematizam a questão do controle de sentidos nas linguagens documentárias. As pesquisas, nesse aspecto, indicam a necessidade de abertura dos sentidos, para que as demandas culturais sejam atendidas, a partir de leituras que sejam mais plurais. Dessa forma, os padrões de classificação não devem ficar presos aos sentidos dominantes que normatizam as unidades de informação.

Nos estudos arquivísticos, em sua relação com a teoria do discurso, o arquivo é visto como uma instituição legitimadora de poder. Vale destacar também que as demandas sociais e o interesse pelas questões identitárias e de inclusão passam a ganhar espaço na arquivística. Acentua-se também que os trabalhos sobre discurso são utilizados no processo de leitura de documentos com viés político e que são destaques no cenário nacional.

Diante das análises realizadas, foi observado que as correntes francófonas de análise do discurso também auxiliaram na explicitação de conteúdos e na organização de informações. Nesse horizonte, a teoria facilitou o processo de agrupamentos e o entendimento das relações existentes entre documentos.

Faz-se mister também enfatizar o papel das vertentes de análise do discurso francesa como uma alternativa metodológica para ciência da informação e para organização do conhecimento, problematizando os aspectos de interpretação para recuperação da informação. Destaque-se o seu uso para análise de textos específicos como, por exemplo, os literários.

As pesquisas também mostraram a possibilidade de se utilizar a análise do discurso foucaultiana como metodologia, para facilitar a compreensão das relações de poder construídas na representação de assunto. Nesse cenário, dada a possibilidade de a representação de assunto refletir apenas elementos da cultura dominante, os profissionais da informação precisam entender as comunidades de usuários e suas demandas sociais específicas. 


\section{Referências}

ALVARENGA, Lídia. A institucionalização da pesquisa educacional no Brasil: estudo bibliométrico dos artigos publicados na Revista Brasileira de Estudos Pedagógicos - 1944-74. 1996. 244 f. Tese (Doutorado) - Universidade Federal de Minas Gerais, Belo Horizonte, 1996.

AZEVEDO NETTO, Carlos Xavier de. A arte rupestre no Brasil: questões de transferência e representação da informação como caminho para interpretação. 2001. 210 f. Tese (Doutorado em Ciência da Informação) - Universidade Federal do Rio de Janeiro / Instituto Brasileiro de Informação em Ciência e Tecnologia, Rio de Janeiro, 2001. Disponível em: http://ridi.ibict.br/bitstream/123456789/684/1/carlosnetto2001.pdf. Acesso em 11 nov. 2018.

BARROS, Dirlene Santos. A lei brasileira de acesso à informação: uma análise da sua construção, do contexto nacional ao contexto político oligárquico do estado do Maranhão (2009-2014). 2017. 236 f. Tese (Doutorado em Ciência da Informação) — Universidade de Brasília, Brasília, 2017.

http://repositorio.unb.br/bitstream/10482/24009/1/2017_DirleneSantosBarros.pdf. Acesso em: 27 ago. 2018.

BARROS, Thiago Henrique Bragato. A construção discursiva em arquivística: uma análise do percurso histórico e conceitual da disciplina por meio dos conceitos de classificação e descrição. 2010. 132 f. Dissertação (Mestrado) - Universidade Estadual Paulista, Faculdade de Filosofia e Ciências, 2010. Disponível em:

https://repositorio.unesp.br/bitstream/handle/11449/93667/barros_thb_me_mar.pdf?sequence =1\&isAllowed=y. Acesso em: 21 ago. 2018.

BARROS, Thiago Henrique Bragato. A representação da informação Arquivística: uma análise do discurso teórico e institucional a partir dos contextos espanhol, canadense e brasileiro. 2014. 222 f. Tese (Doutorado) - Universidade Estadual Paulista, Faculdade de Filosofia e Ciências de Marília, 2014. Disponível em:

https://repositorio.unesp.br/bitstream/handle/11449/110391/000792879.pdf?sequence=1\&isAl lowed=y. Acesso em: 28 ago. 2018.

BOURDIEU, Pierre. Os usos sociais da ciência: por uma sociologia clínica do campo científico. São Paulo: Editora Unesp, 2004.

BOUTET, Josiane; MAINGUENEAU, Dominique. Sociolinguistique et analyse de discours: façons de dire, façons de faire. Langage et société, Paris, n. 4, p. 15-47, 2005. Disponível em: https://www.cairn.info/revue-langage-et-societe-2005-4-page-15.html. Acesso em: 23 jan. 2019.

CAPRIOLI, Mariana da Silva. Análise do discurso literário: proposta de metodologia no processo de análise documental de textos narrativos de ficção. 2018. 104 f. Dissertação (Mestrado) - Universidade Estadual Paulista, Faculdade de Filosofia e Ciências de Marília, 2018. Disponível em:

https://repositorio.unesp.br/bitstream/handle/11449/152778/caprioli_ms_me_mar.pdf?sequenc $\underline{\mathrm{e}=5 \& \text { isAllowed }=\mathrm{y}}$. Acesso em: 07 jan. 2019. 
CORDEIRO, Pedro Aurélio Cerveira. Análise do discurso e Ciência da Informação: ensaio sobre uma possibilidade metodológica. 2004. 93f. Dissertação (Mestrado em Ciência da Informação) - Escola de Comunicação, Universidade Federal do Rio de Janeiro, Rio de Janeiro, 2004. Disponível em:

http://rigeo.cprm.gov.br/xmlui/bitstream/handle/doc/208/diss_pedro_cordeiro.pdf?sequence= 1\&isAllowed=y. Acesso em: 28 ago. 2018.

ELIAS, Aluf Alba Vilar. Arquivo, verdade e o processo de transição democrática no

Brasil: o legado da Comissão Nacional da Verdade para ampliação da discussão epistemológica arquivística. 2017. 163 f., il. Tese (Doutorado em Ciência da Informação) Universidade de Brasília, Brasília, 2017. Disponível em:

http://repositorio.unb.br/handle/10482/32024. Acesso em: 06 jan. 2019.

FERRAREZI, Ludmila. A biblioteca escolar nas teias do discurso eletrônico. 2010. Dissertação (Mestrado em Ciências) - Universidade de São Paulo, Ribeirão Preto. Disponível em: http://www.teses.usp.br/teses/disponiveis/59/59137/tde-12112013-163230/pt-br.php.

Acesso em: 02 jan. 2019.

FOUCAULT, Michel. A arqueologia do saber. Rio de Janeiro: Forense Universitária, 2008.

FREITAS, Lídia da Silva. Na teia dos sentidos: análise do discurso da Ciência da Informação sobre a atual condição da Informação. 2001. 245 f. Tese (Doutorado) - Curso de Ciência da Comunicação, USP, São Paulo, 2001.

GADET, Françoise. 1977: em torno de um momento-chave do surgimento da Sociolinguística na França. Organon, Porto Alegre, v. 30, n. 59, p. 41, 2015.

GUIMARÃES, José Augusto Chaves. Organização do conhecimento: passado, presente e futuro sob a perspectiva da ISKO. Informação \& Informação, Londrina, v. 22, n. 2, p. 84, 2017. Disponível em:

https://www.uel.br/revistas/uel/index.php/informacao/article/view/31443/21993. Acesso em: 9 set. 2018.

HJØRLAND, B. What is knowledge organization (KO)? Knowledge Organization, Würzburg, v. 35, n. 2/3, p. 86-101, 2008. Disponível em: https://repository.arizona.edu/handle/10150/106183. Acesso em: 1 set. 2018.

JAPIASSU, Hilton. Introdução ao pensamento epistemológico. 2. ed. Rio de Janeiro: Livraria F. Alves, 1977.

LIMA, Larissa de Mello. A institucionalização cognitiva e social da Ciência da

Informação no Brasil: uma análise discursiva com base nos anais do GT1 ENANCIB em sua primeira década. 2017. 100 f. Dissertação (mestrado) - Universidade Estadual Paulista, Faculdade de Filosofia e Ciências de Marília, 2017. Disponível em:

https://www.marilia.unesp.br/Home/Pos-

Graduacao/CienciadaInformacao/Dissertacoes/lima_lm_me.pdf. Acesso em: 14 jul. 2021.

LIMA, Marcia Heloisa Tavares de Figueredo. Pela reconstrução epistemológica do direito à informação: um estudo metainformacional da opinio juris brasileira contemporânea. 2004. Tese (Doutorado) - UFRJ/ECO-CNPq/IBICT. Rio de Janeiro, 2004. Disponível em: http://repositorio.ibict.br/bitstream/123456789/699/1/marcialima2006.pdf. Acesso em: 15 dez. 2018. 
LUCAS, Clarinda Rodrigues. Indexação: gesto de leitura do bibliotecário. 1996. Tese (Doutorado) - UNICAMP, Campinas, 1996. Disponível em:

https://bdtd.ibict.br/vufind/Record/CAMP_02ede34fe27ca7fedf1350cc4c636207. Acesso em: 1 out. 2020.

MARCELLESI, Jean-Baptiste. Éléments pour une analyse contrastive du discours politique. Langages, Paris, n. 23, p. 25-56, 1971. Disponível em: https://www.persee.fr/doc/lgge_0458726x_1971_num_6_23_2049. Acesso em: 06 nov. 2021.

MARTINS, Gracy Kelli; MORAES, João Batista Ernesto de. Organização e representação do conhecimento: institucionalização como disciplina científica no âmbito da ciência da informação. In: ENCONTRO NACIONAL DE PESQUISA EM CIÊNCIA DA INFORMAÇÃO, 16., 2015. [Anais...]. João Pessoa: UFPB, 2015. Disponível em: http://www.brapci.inf.br/index.php/article/download/43835. Acesso em: 9 set. 2008.

MATOS, Daniela Fernanda de Oliveira; GUIMARÃES, José Augusto Chaves; GRÁCIO, Maria Claúdia Cabrini. A dimensão conceitual da organização do conhecimento no universo científico da ISKO: uma análise de domínio a partir dos congressos de ISKO-Brasil e ISKOEspanha. In: CONGRESO ISKO ESPAÑA-PORTUGAL, 2., 2015. Organización del conocimiento: sistemas de información abiertos. Universidad de Murcia, 2015. p. 544-555.

MILANI, Suellen Oliveira. Bias na representação de assunto: uma discussão de oposições binárias nos functional requirements for subject authority data (FRSAD). 2014. $134 \mathrm{f}$. Tese (Doutorado) - Universidade Estadual Paulista, Faculdade de Filosofia e Ciências de Marília, 2014. Disponível em: http://hdl.handle.net/11449/110388. Acesso em: 04 jan. 2019.

NARZETTI, Claudiana. As linhas de análise do discurso na França nos anos 60-70. RevLet: Revista Virtual de Letras, Jataí, v. 2, n. 2, 2010.

NOVO, Hildenise Ferreira. Análise conceitual e cognitiva: Modac - um modelo dinâmico para auxiliar à construção de Sistemas de Organização do Conhecimento (SOC). 2014. Tese Universidade Federal da Bahia, Salvador, 2014. Disponível em:

https://repositorio.ufba.br/ri/bitstream/ri/19651/1/Tesefinalcorrigidabanca.pdf. Acesso em: 09 jan. 2019.

ODDONE, Nanci Elizabeth. Ciência da Informação em perspectiva histórica: Lydia de Queiroz Sambaquy e o aporte da Documentação (Brasil, 1930-1970). 2004. 161 f. Tese (Doutorado em Ciência da Informação) - Universidade Federal do Rio de Janeiro, Instituto Brasileiro de Informação em Ciência e Tecnologia, Rio de Janeiro, 2004. Disponível em: http://ridi.ibict.br/bitstream/123456789/691/1/oddone2004.pdf. Acesso em: 16 nov. 2018.

ORLANDI, Eni Puccinelli. Análise de discurso: princípios e procedimentos. 7. ed. Campinas: Pontes, 2007.

ORLANDI, Eni Puccinelli. A análise de discurso em suas diferentes tradições intelectuais: o Brasil. In: SEMINÁRIO DE ESTUDOS EM ANÁLISE DE DISCURSO, 1., 2003, Porto Alegre. Anais... Porto Alegre: UFRGS, 2003. 18 f.

PÊCHEUX, Michel. Semântica e discurso: uma crítica à afirmação do óbvio. 2. ed. Campinas: Ed. Unicamp, 1995. 
REIS, Lívia de Lima. Dos modelos classificatórios tradicionais na ciência da informação à folksonomia: um enfoque discursivo. 2012. 96 f. Dissertação (Mestrado em Ciências Humanas) - Universidade Federal de São Carlos, São Carlos, 2012.

ROCHA, Luisa Maria Gomes de Mattos. Museu, informação e comunicação: o processo de construção do discurso museográfico e suas estratégias. 1999. Dissertação (Mestrado em Ciência da Informação) - Universidade Federal do Rio de Janeiro, Rio de Janeiro, 1999.

SALES, Rodrigo. A organização do conhecimento na comunidade científica brasileira da Ciência da Informação: uma investigação no âmbito da ISKO-Brasil. In: CONGRESSO ISKO ESPAÑA, 12.; CONGRESSO ISKO ESPANHA-PORTUGAL, 2, 2015, Murcia. Anais... Murcia: Universidad de Murcia, 2015. Disponível em: http://www.iskoiberico.org/wp-content/uploads/2015/11/85_Sales.pdf. Acesso em: 9 set. 2018.

SANTOS, Flávia Vieira da Silva. Análise foucaultiana na organização de documentos na web .2013. 94 f. Dissertação - Universidade Federal de São Carlos, São Carlos, 2013. Disponível em:

https://repositorio.ufscar.br/bitstream/handle/ufscar/1121/5563.pdf?sequence=1\&isAllowed= y. Acesso em: 30 ago. 2018.

SILVA, Rachel Polycarpo da. Biblioteca para quem não sabe ler?: a quebra de paradigma sobre leitura, leitores, usuários de bibliotecas e o papel do bibliotecário escolar na educação infantil. 2014. Dissertação - Universidade Federal Fluminense, Niterói, 2014. Disponível em: https://bdtd.ibict.br/vufind/Record/UFF-2_f877fdcad62e3fce9d83296ca6022e08. Acesso em: 1 out. 2020.

SOUZA, Edivanio Duarte de. A epistemologia interdisciplinar na Ciência da Informação: dos indícios aos efeitos de sentido na consolidação do campo disciplinar. 2011. 346 f. 2011. Tese (Doutorado em Ciência da Informação) - Escola de Ciência da Informação, Universidade Federal de Minas Gerais, Minas Gerais. Disponível em: http://www.bibliotecadigital.ufmg.br/dspace/bitstream/handle/1843/ECID-

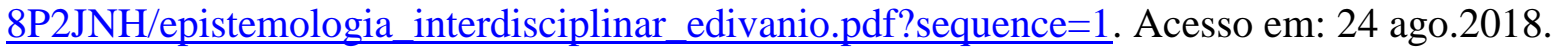

SOUZA, Terezinha de Fátima Carvalho de. Bases de saber: arqueologia da informação sobre transgênicos. 2008. 170f. Tese (Doutorado em Ciência da Informação) - Escola de Ciência da Informação, Universidade Federal de Minas Gerais, Belo Horizonte, 2008. Disponível em: http://www.bibliotecadigital.ufmg.br/dspace/bitstream/handle/1843/ECID7HUGQV/teseversaofinal2009_1_1_.pdf?sequence=1. Acesso em: 20 dez. 2018. 